Noushin Sanjaranipour ${ }^{1}$, Farideh Atabi $^{2}$, Mansour Momeni ${ }^{3}$, Jamal Ghodousi ${ }^{4}$, Akramolmolok Lahijanian ${ }^{5}$

\title{
Investigating the Efficiency of Combined Cycle Power Plants with the Data Envelopment Analysis Process (with an Emphasis on Air Pollution)
}

\begin{abstract}
Performance management is one of the most significant strategies in promoting the efficiency of organizations and is highly sensitive. It is important to check the efficiency of combined cycle power plants because of their major contribution to power generation and air pollution. This study was conducted to evaluate the economic and environmental efficiency of Combined Cycle Power Plants (CCPPs). The inputs and outputs required to evaluate the performance of the power plants were determined according to expert opinions. Then, the 7-year statistics and information of the Qom, Neishabour, Shahid Rajaee, Yazd and Kerman power plants were collected as the desired CCPPs in Iran. The Window Data Envelopment Analysis (WDEA) method was used for evaluating the efficiency of the power plants. The 3-year window length showed that most of the power plants were efficient. Only the Rajaee, Neishabour and Yazd power plants were ineffective in some years. The mean efficiency of the power plants in the 4-year window length showed that the plants were efficient from 2008 to 2010.
\end{abstract}

Keywords: efficiency, Combined Cycle Power Plants, DEA, air pollution

Received: 15 November 2021; accepted: 13 December 2021

(C) 2022 Authors. This is an open access publication, which can be used, distributed and reproduced in any medium according to the Creative Commons CC-BY 4.0 License.

Islamic Azad University, Science and Research Branch, Faculty of Natural Resources and Environment, Department of Environmental Management, Tehran, Iran, email: N.sanjarani2010@gmail.com, (1D https://orcid.org/0000-0002-9740-3900

2 Islamic Azad University, Science and Research Branch, Department of Environmental Engineering, Tehran, Iran, email: far-atabi@jamejam.net (corresponding author), (1D https://orcid.org/0000-0002-8192-2976

3 University of Tehran, Department of Management, Tehran, Iran, email: mmomeni@ut.ac.ir, (10) https://orcid.org/0000-0002-9157-5584

4 Islamic Azad University, Science and Research Branch, Faculty of Natural Resources and Environment, Department of Environmental Management, Tehran, Iran, email: jamal_go@yahoo.com, (D) https://orcid.org/0000-0002-2610-9886

5 Islamic Azad University, Science and Research Branch, Faculty of Natural Resources and Environment, Department of Environmental Management, Tehran, Iran, email: Lahijanian@hotmail.com, (1) https://orcid.org/0000-0002-8452-4324 


\section{Introduction}

Whilst considerable variety has been introduced in terms of the sources of supplying electricity, fossil fuels still play a major role in electricity generation [1]. The consumption of fossil fuels in electricity generation results in the emission of carbon dioxide $\left(\mathrm{CO}_{2}\right)$, nitrogen oxide $\left(\mathrm{NO}_{X}\right)$, sulfur dioxide $\left(\mathrm{SO}_{2}\right)$, particulate matter and liquid and solid contaminants. These pollutants are harmful to both the environment and human health. The most significant environmental impact of fossil fuel power plants is air pollution [2].

According to the studies by the American Electric Power Research Institute (EPRI) in 2000, which were later used in many countries, the third destination of the future direction of the electricity industry, which was expected to be finalized by 2025 (25 years) lay in increasing efficiency, productivity, and economic empowerment. Thus, it is important to study efficiency and strive to increase it in achieving the prospects for the electricity industry and dealing with the challenges ahead. Iran's electricity industry is at a desirable level in terms of production but other issues such as consumption, energy loss, efficiency and productivity of the equipment and facilities urgently need optimization and proper management to reduce consumption. Accordingly, optimum and efficient utilization in the electricity industry has always been the focus of the managers who are active in the Iranian electricity industry [3]. Due to its underlying role and its close relationship with the factors influencing economic, industrial, and dynamic growth, the power generation industry is of paramount importance, so its efficiency and productivity must be promoted. Performance monitoring, and performance management more generally, is a process by which one can gain useful insights into how organizational affairs work to be successful, enhance strengths, and correct or eliminate weaknesses. Performance management is one of the most important strategies for promoting the productivity of an organization and is highly sensitive [4]. Given the major role of power plants in fuel consumption and air pollution, energy consumption and greenhouse gas emissions must be monitored, which is important in terms of several aspects. Firstly, it optimizes fossil fuel consumption and reduces fuel consumption, meaning these valuable resources are preserved for the future. Secondly, controlling the consumption of inputs saves economic costs and reduces production costs, and thirdly, it can protect the environment and prevent climate change. Indeed, improving air quality can have long-term positive effects on the energy structure and environment [5]. In this respect, examining the efficiency of CCPPs given their major contribution to power generation is important.

Performance and efficiency evaluations are one of the main tasks of any organization and one of the aspects of performance management that have been implemented by the use of financial indices [6]. Few studies have been conducted thus far to evaluate the efficiency of power plants, despite air pollutant emissions and related factors; therefore, this study was conducted to examine the economic 
and environmental efficiency of combined cycle power plants. Nowadays, as one of the methods for calculating the efficiency of decision-making units, Data Envelopment Analysis (DEA) has been associated with a great deal of theoretical and practical development. In addition to determining relative efficiency, using DEA patterns identifies the organization's weaknesses in various indices and, by presenting their desired value, identifies the organization policy towards efficiency and productivity improvement. The efficient models, through which inefficient units have been evaluated, are introduced to the inefficient units [7]. In so doing, the inputs and outputs needed to evaluate the performance of the power plants were determined. The appropriate DEA method is selected to evaluate the performance of the power plants according to their inputs and outputs. The power plants were selected based on the available information and, after collecting the relevant information, rankings of CCPPs were made and efficient and inefficient units were identified using the DEA technique. Then, 7-year statistics and information from the Qom, Neishabour, Shahid Rajaee, Yazd and Kerman power plants were collected as the desired CCPPs in Iran. Several studies have been conducted on performance evaluation using DEA. Zhou et al. [8] examined the efficient boundary of DEA and portfolio sustainability principles in China's investment funds. Amiri et al. [9] examined the performance of police sciences departments using the shared weights approach in DEA and decomposition into fuzzy principal components. In this paper, to improve the results of the DEA model, principal component analysis (PCA) and common shared weights approaches were used and a model is presented for data envelopment analysis [9]. Pourghafar Magferati et al. [10] presented a conceptual model for evaluating the performance of Research and Development (R\&D) units of manufacturing companies with the DEA / AHP approach in Guilan. Taking data from the Ministry of Industry, Mines and Trade, with descriptions of the tasks assigned to these units, the inputs and outputs were used to determine the effective indices. The financial aspect with the significance of $447 \%$ was selected as the highest and most influential index and research performance as the lowest index. Then, using the DEA model to evaluate the efficiency of R\&D units, 3 inefficient units and 10 inefficient units were identified. The Anderson-Peterson (AP) model was used to rank the efficient units. The most efficient R\&D unit was related to the Pars Shahab Company, with the R\&D units of Ihagostar and Nika ranked second and third, respectively, among other units [10]. Bagheri [11] evaluated and measured energy efficiency in one of Iran's thermal power plants. The results of his study showed that the productivity of different factors and institutions in that study increased over time and in the process after 2008 with the start of making energy subsidies targeted, the process of optimizing production was begun. Therefore, the technology index has been the most productive and the energy index has shown a positive trend concerning changes [11]. In another study entitled "Prioritizing power plants in Iran using multi-characteristic decision-making models," considering different economic, environmental, political and social criteria, energy and technical security, using dynamic analysis method hierarchies 
for weighting criteria and calculating qualitative criteria and Preference Ranking Organization Method for Enrichment Evaluations (PROMETHEE) for calculating quantitative criteria were evaluated and prioritized for different power generation options. The results of this study showed that wind, hydroelectricity, photovoltaic, combined cycle, nuclear, gas and heater power plants are in the order of priority, respectively [12]. A study also used DEA to measure the efficiency of energy consumption and environmental protection of 29 Chinese enforcement zones in 2000-2008. Their results showed that enforcement areas in the eastern regions of the country had the highest level of energy efficiency and environmental protection while the lowest efficiency was in the western regions. Moreover, the results of the study by Wang et al. [13] showed that the western, eastern, and central regions enjoy high efficiency in energy consumption and environmental protection [13].

WDEA is a popular, effective and practical method for evaluating the dynamic performance of decision-making units (DMUs). It operates on the principle of moving averages and creates performance criteria by considering each DMU in different periods as a separate DMU. Using the WDEA approach, a decisionmaker can measure the performance of different DMUs at different periods through a series of overlapping windows. WDEA can also increase the power of differentiation by increasing the number of DMUs when a limited number of DMUs are available. The main advantage of the WDEA approach is the description of horizontal and vertical changes in the performance of DMUs. In addition, the use of window analysis can increase the power of differentiation by increasing the number of DMUs when a limited number of DMUs are available. Determining the optimal combined cycle power plant is inherently a complex problem, often with multiple and conflicting criteria as well as uncertain factors. The complexity of the problem is combined with the production of undesirable outputs and the existence of natural and managerial capabilities.

In this study, the custom data envelopment analysis (DEA) method was used to solve the problem of power generation and air pollution together. Sustainable electricity generation requires the continuous improvement of power plant efficiency. Given the many applications, importance, and growing trends in the WDEA field, this paper was conducted to evaluate the economic and environmental efficiency of CCPPs, using the WDEA method.

\section{Materials and Methods}

In this study, the effective indices (including quantitative and qualitative criteria) were identified in the performance appraisal. Then, the inputs and outputs were determined and separated to compare the performance evaluation of a set of similar decision units (CCPPs) using the DEA technique according to the priority of effective sub-criteria in performance evaluation. The following steps were taken in this study. 
A number of steps were taken to evaluate the performance of CCPPs (with an emphasis on air pollution) based on the DEA technique and as shown in Figure 1.

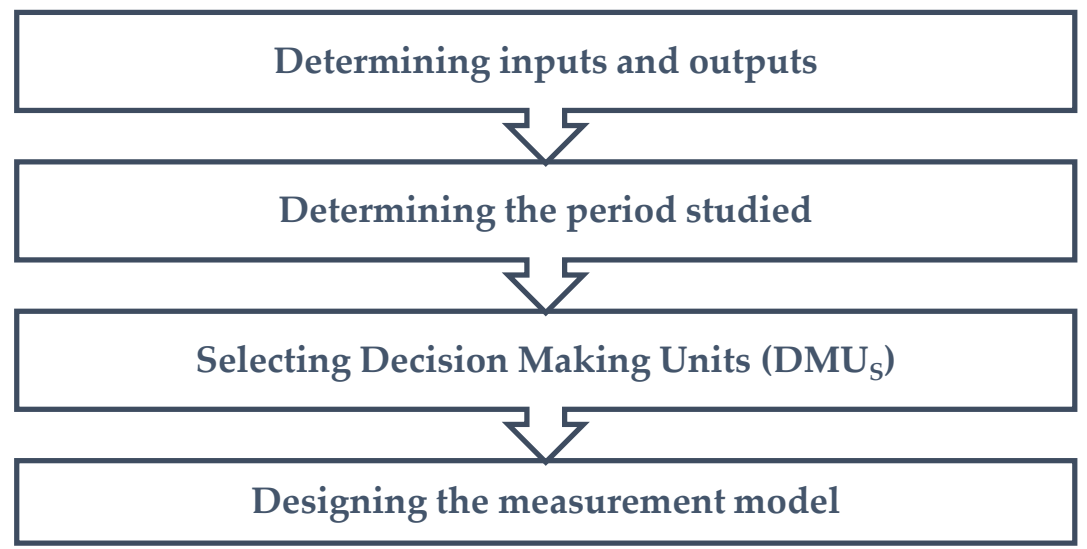

Fig. 1. Research process

\section{Determining the Inputs and Outputs}

Firstly, we surveyed the experts' ideas in the electricity and power industry (30 experts) to identify the most effective and appropriate criteria for the performance evaluation of combined cycle power plants with the emphasis on reducing emissions of air pollutants. The criteria were then separated based on the types and natures of the criteria. In general, in the DEA technique, the criteria are separated into inputs and outputs in two ways:

1) Input is a factor provided to the organization in the form of equipment, facilities, support, and so on so that the organization can use it to produce and achieve its goals. Output is the factor generated by the management of the organization after processing the inputs. Or, in other words, the output is the expectation from the organization after the job.

2) Output is considered to be the factor whose increase, if it retains all other factors, leads to a decrease in efficiency. In contrast, its decrease, if it retains all other factors, increases efficiency. Output is considered to be a factor whose increase in efficiency if all other factors are maintained, increases efficien$\mathrm{cy}$, and its decrease, if all other factors are maintained, decreases efficiency.

Given the subject of the study and the nature of the metrics explained, one can state that inputs are those metrics used in power generation and outputs are those that identify the organization's expectations in establishing and generating electricity in power plants to reduce air pollutants.

In this study, to determine whether the cost of electricity generation alone as an input can measure the efficiency of power plants, analyses are considered in two 
modes. In the first case, all costs are considered as inputs, based on which the efficiency is calculated. Then, in the second case, only the cost of electricity is considered as an input. If the results of the power plants efficiency are the same in both cases, then it shows that the other costs have not affected the efficiency calculation.

\section{Determining the Period}

Due to the limitations of the study and available statistics and information to be used to evaluate the effectiveness of decision-making units, a 7-year evaluation period (from 2008 to 2014) was considered.

\section{Selecting the Decision-Making Units (DMUs)}

The 7-year statistics and information of the Qom, Neishabour, Shahid Rajaee, Yazd and Kerman combined cycle power plants were collected from among the CCPPs in Iran.

\section{Designing the proper performance evaluation model}

To examine the efficiency of power plants over time, the Window model was used in the present study. In this model, as the performance of each plant is compared to its performance in previous years and those of other power plants, there is no need for a high sample size and having data from five combined cycle power plants over 7 years is sufficient to measure efficiency.

If we assume that we have $n$ DMUs where $k$ is the period evaluated, then $p$ shows the length of the window and $w$ shows the number of windows:

$$
\begin{cases}\text { no. of windows } & \omega=k-p+1 \\ \text { no. of DMUs in each windows } & n p / 2 \\ \text { no. of "different" DMUs } & n p w \\ \Delta \text { no. of DMUs } & n(p-1)(k-p)\end{cases}
$$

The maximum number of DMUs is obtained by this equation $\rho=k+1 / 2$ and the window length does not require integration and is modified in the following formulation:

$$
\rho=\left\{\begin{array}{l}
\text { 1) } \frac{k+1}{2} \\
\text { 2) } \frac{k+1}{2} \pm \frac{1}{2}
\end{array}\right\},(\rho \leq k)
$$

Formulation (1) is used if the number of periods is odd and the second is used when the number of periods is even. When the number of periods is even, formulation (2) is written as follows [14]:

$$
n\left[(k+1)\left(\frac{k+1}{2}-\frac{1}{2}\right)-\left(\frac{k+1}{2}-\frac{1}{2}\right)^{2}\right] n\left[(k+1)\left(\frac{k+1}{2}+\frac{1}{2}\right)-\left(\frac{k+1}{2}+\frac{1}{2}\right)^{2}\right]=\frac{n}{4}\left[(k+1)^{2}-1\right]
$$


Now, we assume $n$ DMUs $(j=1,2, \ldots, n)$ in the periods $(t=1,2, \ldots, T)$ with $m$ inputs and $s$ outputs. In these units, a sample containing $(n \times T)$ will be observed and an $n$ observation in period $t, D M U_{t}^{j}$, it has an $m$-dimensional vector of inputs $X_{t}^{j}=\left(x_{1 t}^{j}, x_{2 t}^{j}, \ldots, x_{m t}^{j}\right)$ and an $s$-dimensional vector of outputs $Y_{t}^{j}=\left(y_{1 t}^{j}, y_{2 t}^{j}, \ldots, y_{m t}^{j}\right)$. The window starting from $k(1 \leq k \leq T)$ and having a width of $1 \leq w \leq T$ is shown by $k w$ and has $k \times w$ observations. The matrix of inputs and outputs for window analysis will be as follows [15]:

$$
X_{k w}=\left[\begin{array}{cccc}
X_{k}^{1} & X_{k}^{2} & \ldots & x_{k}^{n} \\
x_{k+1}^{1} & x_{k+1}^{2} & \ldots & x_{k+1}^{n} \\
\vdots & \vdots & \ddots & \vdots \\
x_{k+w}^{1} & x_{k+w}^{2} & \ldots & x_{k+w}^{n}
\end{array}\right], \quad y_{k w}=\left[\begin{array}{cccc}
y_{k}^{1} & y_{k}^{2} & \ldots & y_{k}^{n} \\
y_{k+1}^{1} & y_{k+1}^{2} & \ldots & y_{k+1}^{n} \\
\vdots & \vdots & \ddots & \vdots \\
y_{k+w}^{1} & y_{k+w}^{2} & \ldots & y_{k+w}^{n}
\end{array}\right]
$$

The problem of input-drive $n$ window assuming constant-scale efficiency will be as follows:

$$
\begin{aligned}
& \theta_{k w 1}^{\prime}=\min \theta \\
& \text { s.t. } \lambda X_{k w} \leq \theta_{t}^{\prime} \\
& \lambda Y_{k w} \leq y_{t}^{\prime} \\
& \lambda_{j} \geq 0(l=1,2, \ldots, n \times w)
\end{aligned}
$$

By adding the constraint $\sum_{j=1}^{n} \lambda_{j}=1$ to the above model [16], the input-driven model of window analysis is obtained by assuming variable-scale efficiency. Applying the variable-scale efficiency assumption for this analysis is due to the existence of units of different sizes.

$$
\begin{aligned}
& \theta_{k w 1}^{\prime}=\min \theta \\
& \text { s.t. } \lambda X_{k w} \leq \theta_{t}^{\prime} \\
& \sum_{j=1}^{n} \lambda_{j}=1 \\
& \lambda Y_{k w} \leq y_{t}^{\prime} \\
& \lambda_{j} \geq 0(l=1,2, \ldots, n \times w)
\end{aligned}
$$

The efficiency of each plant is calculated separately in each window and each year. In this study, the evaluation period was 7 years (from 2008 to 2014). The efficiency was done for windows lasting 3 to 4 years. The window analysis technique was used to evaluate the efficiency of power plants, where the inputs and outputs of power plants are collected over different years.

\section{Results and Discussion}

\subsection{Identification of Performance Evaluation Criteria}

During the survey periods, according to the Likert spectrum (5-option), final performance indices of thermal power plants were finalized (Tab. 1). 
Table 1. Performance evaluation criteria

\begin{tabular}{|l|c||}
\hline \multicolumn{1}{|c|}{ Criteria } & Mean \\
\hline \hline Energy consumption (fuel price) & 3.069 \\
\hline Maintenance costs & 3.039 \\
\hline $\mathrm{CO}_{2}$ emission rate & 3.214 \\
\hline $\mathrm{NO}_{X}$ emission rate & 3.313 \\
\hline $\mathrm{SO}_{2}$ emission rate & 3.098 \\
\hline Emission monitoring system & 3.158 \\
\hline The annual power generation rate & 3.669 \\
\hline Investment in green technology and innovation & 3.366 \\
\hline Fuel consumption & 3.276 \\
\hline Fuel type & 3.098 \\
\hline Power plant capacity & 2.964 \\
\hline Power plant life & 3.016 \\
\hline Net Heat Value (HHV) & 3.171 \\
\hline Access to information and knowledge sharing & 3.117 \\
\hline Applying equipment for clean development & 3.470 \\
\hline IMS deployment & 3.270 \\
\hline Occupational safety and health & 3.178 \\
\hline
\end{tabular}

According to the results, Kendall's coefficients in the first, second and third rounds of the Delphi technique were obtained as 0.316, 0.42010, 0.496, respectively, showing that the consensus among the experts was good. Finally, the remaining 18 indices in the third round all again score above 7 in the fourth round. Kendall's coefficient of the agreement was improved and the mean scores of all indices were obtained at about 7 and final indices were identified in Table 1.

\subsection{Research Inputs and Outputs}

All inputs and outputs in the DEA technique are summarized in Table 2.

Table 2. DEA techniques inputs and outputs

\begin{tabular}{|l|l||}
\hline \multicolumn{1}{|c|}{ Input } & \multicolumn{1}{c|}{ Output } \\
\hline Maintenance costs & $\mathrm{CO}_{2}$ emission rate \\
\hline Consumed diesel fuel & $\mathrm{NO}_{X}$ emission rate \\
\hline Natural gas & $\mathrm{SO}_{2}$ emission rate \\
\hline Power plant capacity & Power generation \\
\hline Power plant life & Net Heat Value (HHV) \\
\hline
\end{tabular}




\section{Performance Evaluation of Power Plants through Window Analysis (3-Year Window Length)}

The results of the window analysis are presented in Table 3. As shown, all power plants are evaluated together with each other over 3 years. The window and the addition of the following year to the end of the window will create another window so that all the duplicates of the window cover the length of the evaluation period.

Thus, the efficiency of other power plants can be interpreted in the same way over time. The performance calculation results are given in Table 3.

Table 3. Evaluation of combined cycle power plants over a 3-year window length

\begin{tabular}{|c|c|c|c|c|c|c|c|c|c|c|}
\hline $\begin{array}{l}\text { Power } \\
\text { plants }\end{array}$ & $\begin{array}{c}\text { Mean } \\
\text { window } \\
\text { efficiency }\end{array}$ & \begin{tabular}{|c|} 
Mean \\
efficiency of \\
each window
\end{tabular} & Window & 2014 & 2013 & 2012 & 2011 & 2010 & 2009 & 2008 \\
\hline \multirow{5}{*}{$\begin{array}{l}\text { Shahid } \\
\text { Rajaee }\end{array}$} & - & 1 & Window 1 & - & - & - & - & 1 & 1 & 1 \\
\hline & - & 1 & Window 2 & - & - & - & 1 & 1 & 1 & - \\
\hline & - & 1 & Window 3 & - & - & 1 & 1 & 1 & - & - \\
\hline & - & 1 & Window 4 & - & 1 & 1 & 1 & - & - & - \\
\hline & 1 & 0.998 & Window 5 & 1 & 0.995 & 1 & - & - & - & - \\
\hline \multirow{5}{*}{ Neishabour } & - & 1 & Window 1 & - & - & - & - & 1 & 1 & 1 \\
\hline & - & 1 & Window 2 & - & - & - & 1 & 1 & 1 & - \\
\hline & - & 1 & Window 3 & - & - & 1 & 1 & 1 & - & - \\
\hline & - & 1 & Window 4 & - & 1 & 1 & 1 & - & - & - \\
\hline & 0.999 & 0.996 & Window 5 & 0.988 & 1 & 1 & - & - & - & - \\
\hline \multirow{5}{*}{ Yazd } & - & 1 & Window 1 & - & - & - & - & 1 & 1 & 1 \\
\hline & - & 0.978 & Window 2 & - & - & - & 0.935 & 1 & 1 & - \\
\hline & - & 0.978 & Window 3 & - & - & 1 & 0.935 & 1 & - & - \\
\hline & - & 1 & Window 4 & - & 1 & 1 & 1 & - & - & - \\
\hline & 0.990 & 0.993 & Window 5 & 1 & 0.980 & 1 & - & - & - & - \\
\hline \multirow{5}{*}{ Kerman } & - & 1 & Window 1 & - & - & - & - & 1 & 1 & 1 \\
\hline & - & 1 & Window 2 & - & - & - & 1 & 1 & 1 & - \\
\hline & - & 1 & Window 3 & - & - & 1 & 1 & 1 & - & - \\
\hline & - & 1 & Window 4 & - & 1 & 1 & 1 & - & - & - \\
\hline & 1 & 1 & Window 5 & 1 & 1 & 1 & - & - & - & - \\
\hline \multirow{5}{*}{ Qom } & - & 1 & Window 1 & - & - & - & - & 1 & 1 & 1 \\
\hline & - & 1 & Window 2 & - & - & - & 1 & 1 & 1 & - \\
\hline & - & 1 & Window 3 & - & - & 1 & 1 & 1 & - & - \\
\hline & - & 1 & Window 4 & - & 1 & 1 & 1 & - & - & - \\
\hline & 1 & 1 & Window 5 & 1 & 1 & 1 & - & - & - & - \\
\hline \multicolumn{4}{|c|}{ Mean efficiency per year } & 0.998 & 0.997 & 1 & 0.991 & 1 & 1 & 1 \\
\hline
\end{tabular}


In window analysis, the mean row means the average efficiency per window. In Table 3, the length of each window is 3 years, so the mean efficiency is written every 3 years in rows. In other words, in the first window 3 years: 2008, 2009 and 2010 are calculated, in the second window the efficiency of the power plants in 2009, 2010 and 2011, in the third window, the efficiency of the power plants in 2010, 2011 and 2012 and in the fourth window the efficiency in 2011, 2012 and 2013 and the fifth window the efficiency in 2012, 2013 and 2014. It should be noted that the efficiencies are calculated separately in each window.

In Table 3, if the mean of each row in each window is averaged, the mean power efficiency of each 3-year window is obtained by calculating the five windows for each power plant. Table 4 shows the changes in average power plant efficiency.

Table 4. Mean performance efficiency of power plants during each window

\begin{tabular}{||l|c|c|c|c|c||}
\hline \hline Power plants & $\begin{array}{c}\text { From } 2012 \\
\text { to } 2014 \\
\text { The } 5^{\text {th }} \text { window }\end{array}$ & $\begin{array}{c}\text { From 2011 } \\
\text { to } 2013 \\
\text { The } 4^{\text {th }} \text { window }\end{array}$ & $\begin{array}{c}\text { From 2010 } \\
\text { to 2012 } \\
\text { The 3 } 3^{\text {rd }} \text { window }\end{array}$ & $\begin{array}{c}\text { From 2009 } \\
\text { to 2011 } \\
\text { The 2 }{ }^{\text {nd }} \text { window }\end{array}$ & $\begin{array}{c}\text { From 2008 } \\
\text { to 2010 } \\
\text { The } 1^{\text {st }} \text { window }\end{array}$ \\
\hline \hline Shahid Rajaee & 0.998 & 1 & 1 & 1 & 1 \\
\hline Neishabour & 0.996 & 1 & 1 & 1 & 1 \\
\hline Yazd & 0.993 & 1 & 0.978 & 1 & 1 \\
\hline Kerman & 1 & 1 & 1 & 1 & 1 \\
\hline Qom & 1 & 1 & 1 & 1 & 1 \\
\hline
\end{tabular}

According to the results presented in Table 4, the mean efficiency of the Shahid Rajaee and Neishabour power plants in the first to fourth windows is equal to one, indicating that they were efficient during this period but inefficient in the fifth window (years 2012-2014) (0.998 and 0.996). The Kerman and Qom Combined Power Plants were effective in all windows.

For each power plant per year, several efficiencies are shown according to window length in Table 4. For example, by considering a 3-year window length, for each power plant in the years 2008 and 2014, each one, in 2009, 2013 and 2014, respectively, have two efficiencies, and in the years 2010 to 2012, three efficiencies are calculated for each year and four in 2011. Thus, the average efficiencies can be calculated per year. Therefore, for each year the average efficiency is calculated for each power plant as shown in Table 5 .

Table 5. Average power plant performance efficiency per year

\begin{tabular}{|l|c|c|c|c|c|c|c||}
\hline \multicolumn{1}{|c|}{ Power plants } & 2014 & 2013 & 2012 & 2011 & 2010 & 2009 & 2008 \\
\hline \hline Shahid Rajaee & 1 & 0.998 & 1 & 1 & 1 & 1 & 1 \\
\hline Neishabour & 0.988 & 1 & 1 & 1 & 1 & 1 & 1 \\
\hline Yazd & 1 & 0.990 & 1 & 0.957 & 1 & 1 & 1 \\
\hline Kerman & 1 & 1 & 1 & 1 & 1 & 1 & 1 \\
\hline Qom & 1 & 1 & 1 & 1 & 1 & 1 & 1 \\
\hline
\end{tabular}


The results presented in Table 5 show that most of the power plants were efficient, with only the Rajaee, Neishabour and Yazd power plants inefficient in some years.

\section{Evaluation of Power Plant Inefficiency \\ by Means of the Window Analysis Method (4-Year Window Length)}

The efficiency calculation results are presented in Table 6. As shown, all of the power plants were evaluated according to each other and themselves over 4 years. Hence, the efficiency of other power plants can be interpreted over time.

Table 6. Evaluation of power plant performance efficiency over a 4-year window length

\begin{tabular}{|c|c|c|c|c|c|c|c|c|c|c|}
\hline $\begin{array}{l}\text { Power } \\
\text { plants }\end{array}$ & $\begin{array}{c}\text { Mean } \\
\text { window } \\
\text { efficiency }\end{array}$ & $\begin{array}{c}\text { Mean } \\
\text { efficiency of } \\
\text { each window }\end{array}$ & Window & 2014 & 2013 & 2012 & 2011 & 2010 & 2009 & 2008 \\
\hline \multirow{4}{*}{$\begin{array}{l}\text { Shahid } \\
\text { Rajaee }\end{array}$} & - & 1 & Window 1 & - & - & - & 1 & 1 & 1 & 1 \\
\hline & - & 1 & Window 2 & - & - & 1 & 1 & 1 & 1 & - \\
\hline & - & 0.995 & Window 3 & - & 0.981 & 1 & 1 & 1 & - & - \\
\hline & 0.9979 & 0.996 & Window 4 & 1 & 0.984 & 1 & 1 & - & - & - \\
\hline \multirow{4}{*}{ Neishabour } & - & 0.999 & Window 1 & - & - & - & 0.998 & 1 & 1 & 1 \\
\hline & - & 1 & Window 2 & - & - & 1 & 1 & 1 & 1 & - \\
\hline & - & 1 & Window 3 & - & 1 & 1 & 1 & 1 & - & - \\
\hline & 0.9992 & 0.997 & Window 4 & 0.9882 & 1 & 1 & 1 & - & - & - \\
\hline \multirow{4}{*}{ Yazd } & - & 0.983 & Window 1 & - & - & - & 0.934 & 1 & 1 & 1 \\
\hline & - & 0.961 & Window 2 & - & - & 0.910 & 0.934 & 1 & 1 & - \\
\hline & - & 0.9704 & Window 3 & - & 0.9466 & 1 & 0.9351 & 1 & - & - \\
\hline & 0.9767 & 0.9917 & Window 4 & 1 & 0.9669 & 1 & 1 & - & - & - \\
\hline \multirow{4}{*}{ Kerman } & - & 1 & Window 1 & - & - & - & 1 & 1 & 1 & 1 \\
\hline & - & 1 & Window 2 & - & - & 1 & 1 & 1 & 1 & - \\
\hline & - & 1 & Window 3 & - & 1 & 1 & 1 & 1 & - & - \\
\hline & 0.999 & 0.999 & Window 4 & 1 & 0.996 & 1 & 1 & - & - & - \\
\hline \multirow{4}{*}{ Qom } & - & 1 & Window 1 & - & - & - & 1 & 1 & 1 & 1 \\
\hline & - & 1 & Window 2 & - & - & 1 & 1 & 1 & 1 & - \\
\hline & - & 1 & Window 3 & - & 1 & 1 & 1 & 1 & - & - \\
\hline & 1 & 1 & Window 4 & 1 & 1 & 1 & 1 & - & - & - \\
\hline & & & & 0.997 & 0.920 & 0.994 & 0.990 & 1 & 1 & 1 \\
\hline
\end{tabular}


In window analysis, the mean row means the average efficiency per window. In the table above, the length of each window is 4 years. Therefore, the mean efficiency is written every 4 years in rows. In other words, the 4 years 2008-2011 are calculated first in the first window, in the second window the efficiency of the plants in 2009-2012, in the third window, the efficiency of the plants in 2010-2013 and the fourth window the efficiency in 2011. In each window, the efficiencies were calculated separately, so that the above results are obtained.

In Table 6, if the mean of each row in each window is averaged, the mean performance efficiency of each 4-year window is obtained. As four windows are calculated for each power plant, four averages are obtained. Table 7 shows how power plants have changed over time (decreased, increased or remained constant).

Table 7. Mean performance efficiency of power plants during each window

\begin{tabular}{||l|c|c|c|c||}
\hline Power plants & $\begin{array}{c}\text { From 2011 to 2014 } \\
\text { The } 4^{\text {th }} \text { window }\end{array}$ & $\begin{array}{c}\text { From 2010 to 2013 } \\
\text { The } 3^{\text {rd }} \text { window }\end{array}$ & $\begin{array}{c}\text { From 2009 to 2012 } \\
\text { The 2 }\end{array}$ & $\begin{array}{c}\text { From } 2008 \text { to } 2011 \\
\text { The } 1^{\text {st }} \text { window }\end{array}$ \\
\hline \hline Shahid Rajaee & 0.996 & 0.995 & 0.999 & 1 \\
\hline Neishabour & 0.997 & 1 & 1 & 0.999 \\
\hline Yazd & 0.991 & 0.970 & 0.961 & 0.983 \\
\hline Kerman & 0.999 & 1 & 1 & 1 \\
\hline Qom & 1 & 1 & 1 & 1 \\
\hline
\end{tabular}

According to the results presented in Table 7, the efficiency of the Shahid Rajaee combined cycle power plant in the first window is equal to 1, which is satisfied but in the second, third and fourth windows its efficiency decreased slightly. The Qom combined cycle power plant is efficient in all four windows. The Yazd combined cycle power plant has had little inefficiency over the years.

In the power plants efficiency table, several efficiencies are calculated per year for each power plant concerning the window length; for example, considering the 4-year window length, for 2008 and 2014 each power plant, for 2009 and 2013, two power plants are calculated for the years 2010 and 2012, for three power plants, and 2011, each four power plants are calculated. Thus, the mean performance efficiencies can be calculated per year. Hence, average efficiency is calculated per year for each power plant as shown in Table 8 . The results indicated that all power plants were efficient in 2008-2010.

Table 8. Variations of power plants' performance efficiencies per year

\begin{tabular}{|l|c|c|c|c|c|c|c||}
\hline \multicolumn{1}{|c|}{ Power plants } & 2014 & 2013 & 2012 & 2011 & 2010 & 2009 & 2008 \\
\hline \hline Shahid Rajaee & 1 & 0.983 & 0.999 & 0.999 & 1 & 1 & 1 \\
\hline Neishabour & 0.988 & 1 & 1 & 0.999 & 1 & 1 & 1 \\
\hline Yazd & 1 & 0.956 & 0.970 & 0.950 & 1 & 1 & 1 \\
\hline Kerman & 1 & 0.998 & 1 & 1 & 1 & 1 & 1 \\
\hline Qom & 1 & 1 & 1 & 1 & 1 & 1 & 1 \\
\hline \hline
\end{tabular}




\section{Conclusion}

In this study, the evaluation period was 7 years (from 2008 to 2014), with performance measured for windows lasting 3 to 4 years. The window analysis technique is used to evaluate the efficiency of power plants, which collects inputs and outputs of the plants over different years. The midpoint input of the combined cycle power plants performance each year in the 3-year time window showed that most plants were efficient. Only the Rajai, Neyshabour and Yazd power plants were ineffective for some years. The average power efficiency of the power plants over the 4-year time window showed that the power plants were all efficient in 2008-2010. A review of the power plants' performance showed that Qom and Kerman power plants were more efficient in different years. In the search of factors beyond the used metrics, it was found that MAPNA was the producer of all the power plants except for the Qom Hybrid Cycle power plant. The model and type of turbine and boiler of the Kerman combined cycle power plant and the model and type of turbine, generator and boiler of the Qom power plant were very different from other power plants. Here we can refer to the type of technology used to evaluate performance. Therefore, in future proposals, this criterion can be taken into consideration. The average efficiency of the studied power plants is assumed to be 0.98 on a variable scale. Due to the optimum efficiency of the power plants, it was found to have the capacity to increase efficiency by up to $2 \%$.

Finally, it is worth considering the effects of factors such as fuel quality and sustainable production and the reduction of pollutants on the performance of these plants. It is also suggested to investigate the causes of inefficiency of some power plants. That is, when a power plant does not grow in the process of efficiency and productivity changes of its covered area or even regresses, it can look for the causes. Incentives and punitive policies commensurate with the unit's performance should be considered. Developing a strategy that incorporates customer satisfaction, quality improvement, and reducing fuel consumption and environmental pollution based on current knowledge can be critical to the growth of the company. For example, efficient power plants will be provided with special facilities and support. Competition in the market for sales of power plants generates motivation and creativity to deliver better quality products and services to the market. The competition also enables power plants to increase their efficiency so that they can produce the most fuel with the lowest fuel costs and lowest emissions. The following areas are recommended for further research and improvement:

Criteria such as return on capital, access to components, and cost to exit the circuit should be considered as effective metrics in future studies. In addition, the CO and PM criteria as other pollutants resulting from power plants should be considered. Extending the scope of research to political variables such as sanctions or implementing policies such as targeting subsidies can provide more information about the variables under investigation and factors affecting energy efficiency. Performance 
with more DMUs should be analyzed for greater model resolution. Other methods such as fuzzy/grey analysis and neural networks should be used as an optimal way to express estimates more precisely because the DEA lacks a predictive capacity.

\section{References}

[1] Key World Energy Statistics 2017. International Energy Agency, Paris 2017.

[2] Samadi S.: The Social Costs of Electricity Generation - Categorising Different Types of Costs and Evaluating Their Respective Relevance. Energies, vol. 10(3), 2017, 356. https://doi.org/10.3390/en10030356.

[3] Amani N., Bagherzadeh Valami H.: Efficiency Evaluation of regional electronic companies in Iran by Network DEA: A based on the Conversion of the Structures into a uniform structure. Journal of Decisions and Operations Research, vol. 3(3), 2018, pp. 249-280. https://doi.org/10.22105/dmor.2018.81213.

[4] Shoghli A., Roshenas K.: Application of Balance Score Card (BSC) and Analytic Hierarchical Process (AHP) in assessment of academic departments: A case study in Zanjan School of Pharmacy. Journal of Medical Education Development, vol. 9(22), 2016, pp. 53-63.

[5] Wen Z., Meng F., Chen M.: Estimates of the potential for energy conservation and $\mathrm{CO}_{2}$ emissions mitigation based on Asian-Pacific Integrated Model (AIM): the case of the iron and steel industry in China. Journal of Cleaner Production, vol. 65, 2014, pp. 120-130. https://doi.org/10.1016/j.jclepro.2013.09.008.

[6] Fallah Shams lialestanei M., Raji R., Khajeh Poor K.: Performance Evaluation by Using Hybrid Method: BSC, TOPSIS and AHP. Industrial Management Journal, vol. 5(1), 2013, pp. 81-100. https://doi.org/10.22059/imj.2013.35684.

[7] Adabi Firouzjah J., Mozafari S.A.A., Hadavi F.: Measuring the efficiency of provincial administrations of the ministry of sport and youth by using data envelopment analysis. Research in Sport Management and Motor Behavior, vol. 3(6), 2014, pp. 61-78.

[8] Zhou Z., Xiao H., Jin Q., Liu W.: DEA frontier improvement and portfolio rebalancing: An application of China mutual funds on considering sustainability information disclosure. European Journal of Operational Research, vol. 269(1), 2018, pp. 111-131. https://doi.org/10.1016/j.ejor.2017.07.010.

[9] Amiri M., RamezanZadeh S., Khatami FirozAbadi M., Sadaghiani J.: Performance Evaluation of Amin Olum-e-Entezami University Departments by Common Weights Approach in Data Envelopment Analysis and Fuzzy Principal Component Analysi. Resource Management in Police, vol. 1395(14), 2016, pp. 11-36.

[10] Pourghafar Maghfertay A., Pishgar F., Gharakhani D.: Providing a conceptual model to evaluate the performance of $R \mathcal{E} D$ departments of manufacturing companies with the approach of DEA/AHP (case study: Gilan province). Journal of Industrial Management, vol. 9 (special issue on management and accounting), 2014, pp. 25-40. 
[11] Bagheri F.: Evaluation and measurement of energy efficiency in one of the thermal power plants of Iran. Case study (Shahid Rajaei Power Plant). Tehran Science and Research Branch, Islamic Azad University, 2015.

[12] Manzoor D., Rahimi A.: A Comparative Analysis of the National Iranian Oil Company (NIOC) Articles of Association during 1954-1978: Proposing a Number of Principles of the New Articles of Association. Iranian Energy Economics, vol. 4(14), 2015, pp. 191-215. https://doi.org/10.22054/jiee.2015.1067.

[13] Wang K., Yu S., Zhang W.: China's regional energy and environmental efficiency: A DEA window analysis based dynamic evaluation. Mathematical and Computer Modelling, vol. 58(5), 2013, pp. 1117-1127. https://doi.org/10.1016/ j.mcm.2011.11.067.

[14] Cooper W.W., Seiford L.M., Tone K.: Data Envelopment Analysis: A Comprehensive Text with Models, Applications, References and DEA-Solver Software. Vol. 2. Springer, 2007.

[15] Asmild M., Paradi J.C., Aggarwall V., Schaffnit C.: Combining DEA Window Analysis with the Malmquist Index Approach in a Study of the Canadian Banking Industry. Journal of Productivity Analysis, vol. 21(1), 2004, pp. 67-89. https://doi.org/10.1023/B:PROD.0000012453.91326.ec.

[16] Banker R.D., Charnes A., Cooper W.W.: Some Models for Estimating Technical and Scale Inefficiencies in Data Envelopment Analysis. Management Science, vol. 30(9), 1984, pp. 1078-1092. https://doi.org/10.1287/mnsc.30.9.1078. 